Review Article

\title{
A review of the development of sport hypnosis as a performance enhancement method for athletes
}

\begin{abstract}
The purpose of this review was to trace the historical milestones in the emergence of sport hypnosis from its earliest beginnings to the present time. The authors reviewed some important definitional conceptualizations of hypnosis from the work of Braid, Bernheim, Freud, Hull and Erickson. Erickson laid the groundwork for the modern definitions of hypnosis and eventually of sport hypnosis. Clinical sport hypnosis was defined as: "helping athletes overcome a variety of psychological symptoms and problems"1 Attention was given to both research and conceptual literature on the role of hypnosis in sport. Contributions of leading sport psychologists, e.g., Bruce Ogilvie, Lars-Eric Uneståhl, Terry Orlick, Ken Ravizza, Brent Rushall, Robert Nideffer, Kay Porter, Maxwell Maltz, whose work in mental training, laid the foundation for sport hypnosis were presented. Finally, the future of sport hypnosis was explored as an empirically demonstrated methodology for expanding the range of mental skills training.
\end{abstract}

Keywords: hypnosis, altered state of consciousness, flow, performance enhancement, sport hypnosis,mental training
Volume 6 Issue 6 - 2016

\author{
William F Straub,' John J Bowman² \\ 'Sport Science International, Lansing, USA \\ ${ }^{2}$ Mind Plus Muscle Institute, Port Jefferson Station, USA \\ Correspondence: William F Straub, Sport Science \\ International, Lansing, USA, Email wstraub73|4@gmail.com
}

Received: July 10, 2016 | Published: November 01, 2016

\section{Method for athletes}

Whether it is overcoming a mental block, building a sharper focus for mental imagery, or increasing self-confidence, Sport Hypnosis has been helping athletes and coaches engage in an elusive but effective mental process to improve training and performance for more than 100years.

\section{Hypnosis defined}

To understand sport hypnosis it is first necessary to define hypnosis and then move to a discussion of how hypnosis is used in sport psychology. From these definitions, a definition of sport hypnosis will evolve. And, although there are many definitions depending on the orientation of the hypnotist, a few definitions are of particular importance. According to the American Psychological Association's Div. 30 (Society of Psychological Hypnosis), "hypnosis is a procedure during which a health professional or researcher suggests while treating someone, that he or she experience changes in sensations, perceptions, thoughts or behavior". According to Robertson, ${ }^{2}$ one of the first definitions of hypnosis was proposed by James Braid, the Scottish physician and surgeon. Braid founded hypnotherapy and first discovered hypnosis in 1841. Originally, he used the term "NeuroHypnotism" or nervous sleep to describe hypnosis. Induced by a fixed and abstracted attention of the mental and visual eye, Braid ${ }^{3}$ thought that hypnosis created a peculiar state of the nervous system. ${ }^{4}$

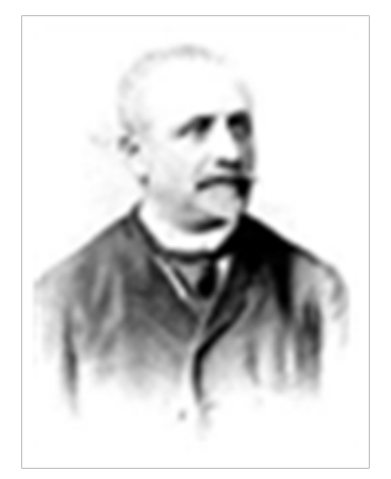

Considered the father of modern hypnotherapy, Hippolyte Bernheim ${ }^{5}$ popularized the view that hypnosis, induced by means of suggestion, is fundamentally a state of heightened suggestibility. Defining hypnosis as induced sleep, Benheim indicated that this definition was to narrow a meaning of the word. He defined hypnosis as "the induction of a peculiar psychical condition which increases the susceptibility to suggestion. ${ }^{5}$ Hyper-suggestibility, with or without sleep, is the term he used to describe a wider definition of hypnosis. ${ }^{5}$

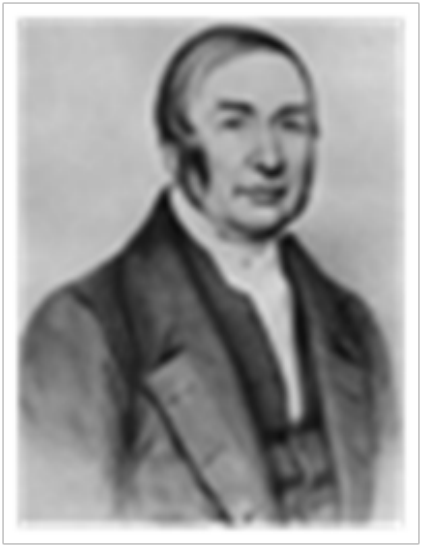

After studying with Bernheim, Sigmund Freud ${ }^{6}$ used hypnosis as a vehicle for catharsis and regression. After abandoning hypnosis, he developed his own technique of psychoanalysis. When Freud returned to hypnosis, he decided that it might be necessary to combine the findings of psychoanalysis with the methods of hypnotherapy. In 1885 Freud was impressed by Charcot's work in France and decided to study with him. Freud was impressed by the therapeutic potential of hypnosis for neurotic disorders. As a result when he came home to Vienna, he used hypnosis to help neurotics recall disturbing events that they had apparently forgotten. After developing his system of psychoanalysis, including theoretical considerations, he encountered problems in hypnotizing some patients. As a result of these difficulties, Freud discarded hypnosis in favor of free association. Eventually, Freud's work led to the development of a school of hypnosis known 
as Hypnoanalysis. Freud did not actually define hypnosis. Rather, he presented a view on the nature of hypnosis. According to Freud, ${ }^{6}$ it has been established that it is possible by means of hypnosis to put a person into a quite peculiar mental state, very similar to sleep.

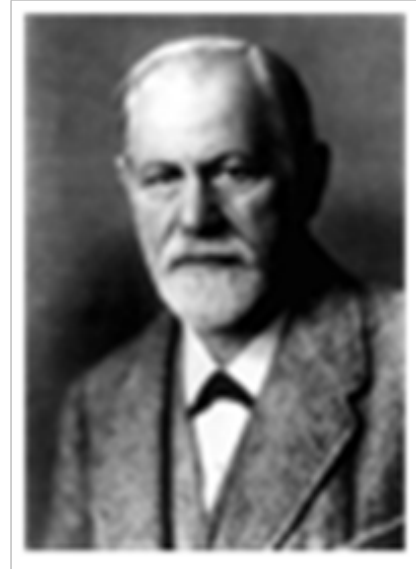

Clark Hull, ${ }^{7}$ a professor of psychology at the Universities of Yale and Wisconsin, helped the evolution of hypnosis by examining it from a scientific perspective. In his text: Hypnosis and Suggestibility, now considered a classic, he indicated that the only thing which seems to define hypnosis as such and which gives any justification for the practice of calling it a 'state' is its generalized hyper-suggestibility. Hull desired to make hypnosis an exact science. And after examining the work of previous experts, he concluded: Despite different theoretical orientations of the various writers and their varying be their diverse interpretation of the phenomenon, most agree that hypnotic trance produces a elevated susceptibility to suggestions.

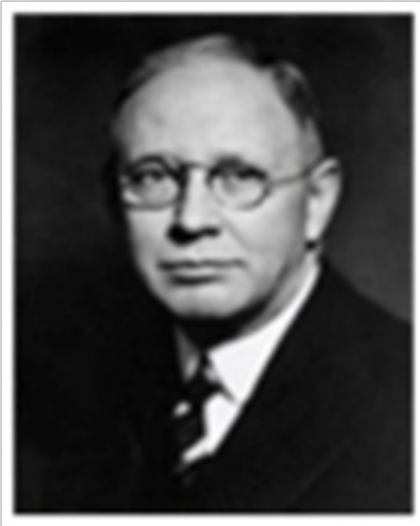

In 1923, Milton Erickson was a second year undergraduate when Clark Hull delivered his lectures on hypnosis at the University of Wisconsin - Madison. This event changed Erickson's life and eventually the study and practice of hypnosis. Today, Erickson is often referred to as the most skilled hypnotherapist of the 20th century. Erickson is the originator of a novel and distinctive style of hypnotism, referred to as "Ericksonian". ${ }^{2}$ Erickson $^{7,8}$ believed that the unconscious mind was always attending to stimuli and indicated that indirect suggestion or what has he called conversational hypnosis that permitted the unconscious mind to participate actively in the therapeutic process. As a result, a normal conversation may induce a hypnotic trance or a therapeutic change in the person. For purposes of conceptualization, he described the hypnotic trance as a state of increased awareness and responsiveness to ideas (Collected Papers, vol. IV, 174) in which the primary feature was suggestibility.

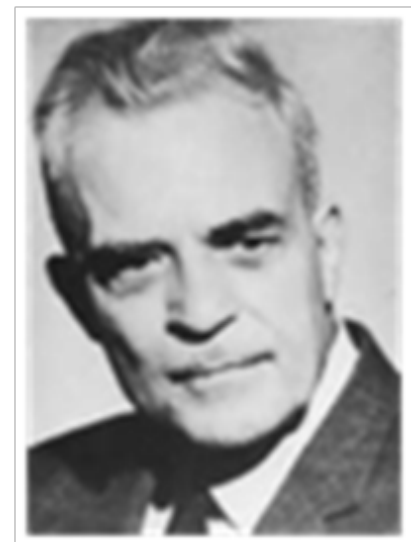

\section{American society of clinical hypnosis (ASCH)}

Using the metaphor: using a magnifying glass to focus the ray of the sun to make it more powerful, The American Society of Clinical Hypnosis (www.asch.net), defines "hypnosis as a state of inner absorption, concentration and focused attention. As a result, when our minds are concentrated and focused, we are able to use our minds more powerfully. While there is general agreement that certain effects of hypnosis exist, there are differences of opinion within the research and clinical communities about how hypnosis works. Some authorities believe that hypnosis can be used by individuals to the degree they possess a hypnotic trait, i.e., traits like those associated with height, body size, hair color, etc." (p.1) Others who study and research hypnosis indicate that there are strong cognitive and interpersonal components that affect an individual's response to hypnosis. There is also growing support for the idea that hypnotic communication and suggestions effectively changes aspects of the person's physiological and neurological functioning.

\section{Summary}

After tracing the history of the development of definitions of hypnosis several themes emerge. First, hypnosis produces an altered state of conscious where the client is able to accept suggestions from the hypnotist. Second, hypnosis is characterized by concentration and focused attention. Presently, hypnosis may be defined as "an induced altered state of consciousness characterized by receptivity to direction and heightened suggestibility". ${ }^{1}$

\section{Definition of sport hypnosis}

Like hypnosis, there is considerable disagreement about how sport hypnosis should be defined. Psychologists seem to favor cognitive and behavior definitions. On the other hand, exercise and sport scientists present a more applied or coach oriented definition. For example, the American Psychological Association, Division 30, to enhance performance, sport hypnosis is defined as the use of hypnotherapy. Paccagnella ${ }^{9}$ agrees and states that sports hypnosis refer to the use of hypnotherapy with athletes to help them perform better, i.e., enhance performance. She further states that hypnosis in sport has therapeutic and performance-enhancing functions and describes it as mental training. Leading authorities Edgette and Rowan ${ }^{1}$ stated that: "Clinical Sport Hypnosis is helping athletes overcome a variety of psychological symptoms and problems" (p.3). They also suggest clinical sport hypnosis can help athletes acquire certain cognitive, psychological, behavioral and affective qualities so that their physical and mental capabilities are improved. According Wikipedia, ${ }^{10}$ sport hypnosis is defined as the use of hypnotherapy with athletes in order 
to improve sporting performance. Liggett ${ }^{11}$ also defines sport hypnosis as a form of mental training which can contribute to enhancing athletic performance.

From the above, it appears that sport hypnosis may be defined as: Hypnotism directed towards improving sports performance. Certain trance phenomenon make hypnosis particularly suited to sports improvement. First is the enhanced vividness and clarity of mental rehearsal or visualization. A figure skater, for example, might use sports hypnosis to vividly imagine doing the double axel or flip or a baseball player might clearly image the perfect swing. The second phenomenon is the intensification of emotions which can create selfconfidence and positive expectations. Finally, sport and hypnosis are both about focusing attention, vivid sensory and physical experience and positive visualization.

\section{Discussion of hypnosis in applied sport psychology}

Among the leading textbooks in sport psychology, only Van Raalte and Brewer ${ }^{12}$ include an article on sport hypnosis. Weinberg and Gould, ${ }^{13}$ in their classic textbook, devote two pages to sport hypnosis. They indicate that hypnosis is "a somewhat controversial and misunderstood technique for reducing anxiety" (p. 273). Apparently other authors such as Martens, ${ }^{14}$ Horn $^{15}$ and Williams ${ }^{16}$ believe that hypnosis is too controversial to be given extensive treatment in their documents. However, Cowan ${ }^{17}$ indicates that there is extensive antidotal and an abundance of case studies that show that hypnosis may improve sport performance. Over the past 50years there have been many reviews of the literature on sport hypnosis. For example, Jacobs $\&$ Gotthelf ${ }^{18}$ examined the effectiveness of hypnosis in enhancing muscular strength and endurance, better motor coordination, and performance in a variety of athletic activities. They reported that there is extensive clinical evidence to support these claims but experimental evidence is lacking.

Morgan ${ }^{19}$ was one of the first sport psychologists to address hypnosis from empirical and clinical perspectives and reviewed such important topics as research and appraisal, qualifications of practitioners, theories, case studies and clinical applications. Morgan also cites the empirical studies of Warren Johnson ${ }^{20}$ at the University of Maryland on the effect of hypnosis on improving the performance of a professional baseball players who was in a slump. In his appraisal of research, Morgan ${ }^{19}$ indicates that most of the investigation have been conducted in laboratory setting and are therefore lacking in ecological validity. An important finding during the early years of sport hypnosis was that perception of effort could be systematically decreased or increased systematically by hypnosis during exercise. ${ }^{20,21}$ However despite some positive findings, a problem with research during this period was that 'demand characteristics' were largely ignored. Morgan concludes his analysis of the research literature by stating that direct hypnotic suggestions is not likely to result in improved performance. Presently, there is renewed appreciation and interest in the use of hypnosis in sport setting. Today research findings are much more positive about the usefulness of hypnosis to improve athletic performance.

One of the most thorough reviews of the conceptual and research literature was completed by Taylor, Horevitz and Balague. ${ }^{22}$ Their paper showed the value of hypnosis in applied sport psychology and addressed hypnotizability and other factors influencing the effectiveness of hypnotic interventions. Tracing sport hypnosis back to it's origins $100 y e a r s$ ago, they described a rich tradition as well as a history of controversy in which despite growing support for the use of hypnosis for athletes, little formal consideration had been given to how hypnosis may be best applied to enhance sport performance. ${ }^{23}$ They describe hypnosis as a state of heightened focal attention where clients are able to manipulate and modify attentional focus. However like Morgan, they note that experimental research about the effect of hypnosis on sport performance had produced mixed results, i.e., the data are equivocal. ${ }^{24,25}$ They conclude their review by stating that hypnosis is useful in applied sport psychology but several important issues must be addressed. For example, the preparation of the hypnotist is of prime importance. Second, APA's ethical standards must be followed by all hypnotists, and third, there is a need for greater methodological rigor in the conduction of sport hypnotic research. Recent empirical investigations have focused on experimental research designed to determine to what degree hypnosis can be used to enhance sport performance ${ }^{26,27}$ studied flow states and hypnosis on golf putting execution. These investigators reported that participants, after receiving the hypnotic intervention, each of the five participants increased their golf putting performance. However, Grindstaff and Fisher ${ }^{28}$ cogently point out that a problem with this investigation was that a control group was not used. In other words, how would golf putting be affected if the hypnotic intervention was removed?

To address this limitation, Pates, Oliver, and Maynard's ${ }^{26}$ conducted a follow-up investigation utilizing a single-subject replication reversal (A-B-A) design. They demonstrated how jump and setshot performance would be affected when hypnotic intervention was introduced and then later removed. The A-B-A design allowed the investigators to establish a baseline assessment, implement the hypnosis technique, and then withdraw the intervention in to determine the effectiveness of the invention. They found that the hypnotic intervention improved jumping and basketball shooting execution. When the experimental treats were removed, the performance scores returned to near baseline levels. Grindstaff and Fisher ${ }^{28}$ have also published and important investigation of the use of sport hypnosis by sport psychology consultants. Six sport psychology consultants (all $\mathrm{PhDs}$ ) conducted in-depth interviews (semi-structured). Each consultant possessed experience and training related to hypnosis. Data analyses revealed a variety of subthemes and themes related to the practice of hypnosis. The guiding interview questions were:

\section{a. hypnosis experience and training,}

b. misconceptions and stereotypes related to hypnosis,

c. the use of hypnosis as a performance enhancement method,

d. advantages and disadvantages of using hypnosis with athletes, and

\section{e. cultural questions. ${ }^{29}$}

Their findings indicated that ethical guidelines addressing the use of sport hypnosis warrant further discussion along with a more stringent review of qualification standards for those consultants providing sport hypnosis to athletes.

\section{Misconceptions about hypnosis}

One of the main factors that limit the use of hypnosis in exercise and sport setting is the misconceptions surrounding its use. Duncan ${ }^{30}$ reported that the debate over hypnosis evolved because of a lack of a clear understanding of how to administer hypnosis, i.e., how it works. "As a consequence, the topic of hypnosis is often viewed with suspicion and mistrust and in the field of magic not science" (p 1). Another limiting factor in the use of hypnosis as a sport enhancement intervention is the lack of qualified sport hypnotists. Many mental trainers lack the expertise needed to perform hypnosis 
and are generally fearful that their clients will not accept it as a viable method of performance enhancement. However despite sound methodological support, the use of hypnosis as a means of enhancing sport performance has increased over the past several years. ${ }^{31}$

Now, let us examine some of these misconceptions. Edgette and Rowan ${ }^{1}$ addressed some of the most prominent misconceptions about sport hypnosis in the $\mathrm{Q}$ and $\mathrm{A}$ :

\section{a. Can I get out of trance once I'm hypnotized??}

No, you are in control. If the hypnotist stopped talking to with you, soon you would either drift off to sleep or you'd awake to see what is going on.

\section{b. Will I express that would embarrass me?}

Even in a hypnotic trance, you are aware of your actions. No! You are the one in control of what you do and say.

\section{c. What does it feel like to be hypnotized?}

Personally, every time I was hypnotized I felt fantastic, i.e., like I had had a good night's sleep. It is very relaxing but perhaps different for each person. Most people report that they feel, uncaring about everyday concerns, relaxed and only vaguely aware of their surroundings, focused on their imagination, barely hearing extraneous noises, a sense of lethargy, arms and legs either heavy or light. To a hypnotist, the person looks as relaxed as if she were asleep. In particular, the face is a little flushed and becomes placid. The eye lids may flutter a little.

\section{d. Sport hypnosis is only about anxiety reduction.}

It is the opinion of Edgette and Rowan ${ }^{1}$ that most athletes do not want or need to experience deep relaxation prior to or during their athletic performances. They continue by saying that most athletes in fact value the experience of being on edge, psyched up, and pumpedup. Too often in the psychological preparation of players, there is a gross overemphasis on relaxation and the athletes feel that they will be 'flat' when it is time to compete.

e. It is vital prior to performance for athletes to visualize a perfect performance.

Edgette and Rowan ${ }^{1}$ state that visualization can be useful but they believe that there is a gross over emphasis on the use of imagery to enhance performance. According to these authors, "most athletes benefit not from visualizing a best scenario but the experience of having a mental stance, or a process, or a strategy that allows them to deal with the many personal and team glitches that arise during the course of any event" (p. 22).

f. Another misconception is that sport psychology involves and extended of therapy.

Edgette and Rowan ${ }^{1}$ indicate that this line of thinking is a carry-over from psychoanalytic and psychodynamic thinking. These therapists believed that any problem, large or small requires an extended period of therapy. Thanks to the work of Milton Erickson's conversation style of psychotherapy, hypnotherapists recognize that most small problem and many large one can be ameliorated in a relatively short time.

g. Another misunderstanding reported by Edgette et al., ${ }^{1}$ is that improving performance through therapy entails uncovering deep psychological issues that are remotely but definitely related to the performance issue at hand. Edgette and Rowan ${ }^{1}$ believes the sport related problems many times are due to a numerous factors, including: poor training, injury, lack of opportunity, habits, lack of confidence and other factors.

As the field of sport hypnosis develops, many of the above misconceptions will disappear as athletes and coach will speak publically about their experiences with hypnosis in practice and competitive situations.

\section{Does Sport Hypnosis Work?}

Although there is a considerable antidotal data that show that hypnosis will help athletes improve their performance Taylor, et al., ${ }^{32}$ indicate that there is only limited empirical investigation that supports these reports. Since Taylor's review was completed in 1993 , new findings have emerged from the literature. In 2010 for example, Cowan completed a doctoral dissertation on the effect of passive and active hypnosis inductions on reaction time with NCAA baseball players. Although her intervention did not improve reaction time, she cited several outcome studies that supported the use of hypnosis. ${ }^{33}$ In addition, Smith, Glass and Miller ${ }^{34}$ published meta-analytic studies on sport hypnosis. They found significantly enhanced effects than nonhypnotic therapies. Additionally, Barker, et al. ${ }^{35}$ found sport hypnosis effective in helping athletes to develop and maintain the appropriate states of mind needed for peak performance as well as increasing their actual ability to perform. They reported that sport hypnosis enhanced the focus of athletes, reduced muscle tension and increased motivation and self-confidence.

Barker, Jones and Greenlees ${ }^{35}$ used hypnosis to assess the immediate effect of soccer wall-volley performance and self-efficacy. The participant $(N=59)$ were college soccer players who were assigned randomly to ether a video attention-control group $(\mathrm{n}=29)$ or hypnosis $(\mathrm{n}=30)$. With an additional 4-week follow-up, a pretestposttest design was used to assess the effects of the experimental treatments. A task-specific questionnaire was used to measure selfefficacy. Findings showed that the hypnosis group, who followed the intervention, performed more effectively and were more efficacious than the control group. Barker et al. stated that hypnosis may be used to improve wall-volley skill and maintain self-efficacy. After a careful review of the research and conceptual literatures, it is evident that hypnosis may be used by athletes and coaches to enhance self-efficacy and improve athlete performance.

\section{Laying the foundation for sport hypnosis--- mental training leaders}

There are a number of outstanding Sport Psychologists who have made the mental training of athletes an integral part of the athlete's preparation and have devoted countless hours to the promotion of sport psychology as a science. Not all of these remarkable men and women would endorse hypnosis as a training modality; however their ideas laid the ground work for the development of new and better mental training methods. The sport psychology profession is indebted to them for their expertise and willing to explore the inner workings of the minds of players.

Dr. Ogilvie was a pioneer in the early days of sport psychology. The first sport psychologist to use assessments and interventions to sport participants, Dr. Ogilvie is recognized for his many and diverse contributions. Ogilvie is often called the "Father of North American Sport Psychology". In the 1970s, he tested 250 race car drivers, skydivers and players from a variety of sports. His research indicated that athletes in risky sports have emotional stability, superior intelligence, and independence when compared to those who did not participate in these sports, Dr. Ogilvie also found that these participants 
make efforts to minimize risks in the sports that they play. His research also indicated that these athletes share certain characteristics. Race car drivers, for example, are very driven and need to be in control. To combat the stress, drivers are also abnormally sexually active. In another investigation, According to Ogilvie, fifty percent of people do not participate during the week in any activities that cause them to sweet. However, attending sporting events, according to Dr. Ogilvie, may not be a passive pastime. Many spectators are very active cheering and praising their teams.

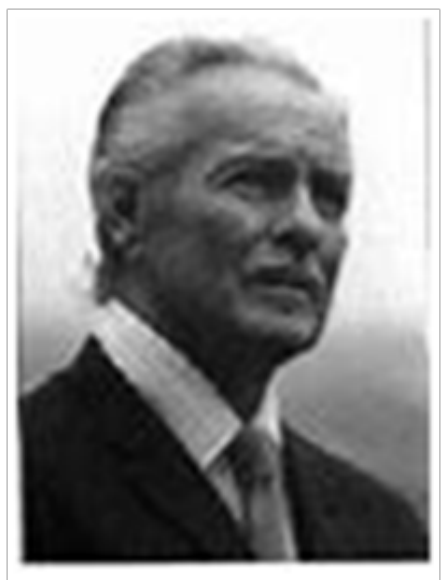

Continuing a line of research on people who attend or watch sports watch on TV, Dr. Ogilvie concluded that persons who watching sports use many social and psychological skills. According to Ogilvie, men while watching sports exude a considerable amount of thee male sex hormone, i.e., testosterone. Ogilvie suggested that when a person watches a sporting event, it provides a fantasy escape for that person and can be a form of hero modeling. Sporting activities, according to Ogilvie, provide people with a sense of social meaning and purpose. During the 1970s when Ogilvie and Thomas Tutko began working with professional athletes, they wrote the controversial text titled: Problem Athletes and How to Handle Them.

During his long career, Dr. Ogilvie consulted with many professional and college/university sports teams. All toll, he worked with a total of four NFL teams, nine NBA teams, and six MLB teams. Some examples of those teams are the New York Mets. Los Angeles Lakers, San Francisco 49ers, and the Dallas Cowboys. From 1960 until his death in 2003, Dr. Ogilvie was also an Olympic consultant for the United States.

With all the increased attention given to sport hypnosis within the past several years, mental training programs have been developed to enhance performance in actual athletic settings. As a young college professor, one of the first times that I heard of sport hypnosis was a talk given by Dr. Lars-Eric Uneståhl at SUNY Oswego. And although he presented many important concepts about sport hypnosis, his demonstration of the "Arm Bar" method of mind control still stays in my thoughts. Dr. Uneståhl asked a young athlete to come to the front of the room and position his arm out to the side with elbow extended. Then he proceeded to push the player' arm down toward the floor while the young man resisted. Then he had the athlete visualize his arm as a crowbar and he attempted to push the arm toward the floor again. This time Dr. Uneståhl found it much more difficult to do so Yes, the mind is very powerful and our thoughts influence how well we behave. Since his talk at Oswego, many mental training programs have been developed to help athletes enhance their individual and collective performances and improve their quality of life. However,
Dr. Uneståhl is recognized as the 'Father' of Mental Training. LarsEric, as everyone calls him, has traveled all over the world promoting mental training as an important component of athletic preparation. His 2013 text with Gregor Schill Coaching with Mental Training: The ideal combination, spells-out his theoretical and applied approach to athlete preparation. And what is so interesting and important about the Unestål's method is that he has the data to support his statements. He has trained hundreds of Swedish athletes and has dramatically shown that metal training, when coupled with physical preparation, is more effective than the use of either one alone.

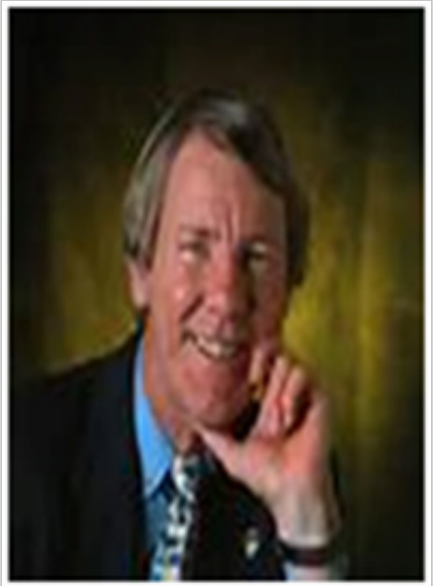

Brent Rushall, a professor emeritus at San Diego State University, is a behavioral oriented scholar who was a leader in the development of mental training programs for players. During his distinguished career he wrote 57 books and published 450 articles dealing the behavioral aspects of sport psychology. Dr. Rushall was a four-time Olympic Team psychologist for Canada. The founding scholar in Behavioral Sport Psychology, Dr. Rushall was also a world authority in the science of coaching. At many world conferences, he was the keynote speaker for both academia and sport psychology. Now in retirement, Professor Rushall has received prestigious awards that recognize his accumulated contributions to the field of the sport sciences. His book: Mental skillsTraining for Sports is a classic (2008).
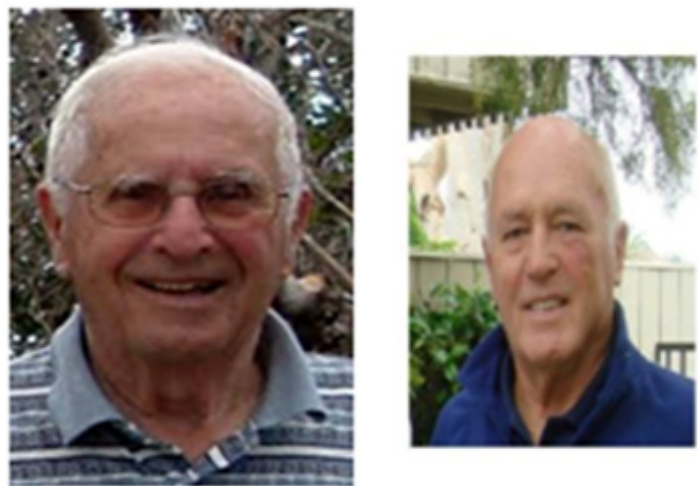

Kay Porter was another early pioneer in the field of mental training. She was one of the first women to us mental training techniques to enhance sport performances of athletes and her writing of visualization scripts is well known. Based in the running capital of the world, Eugene, Oregon, Dr. Porter's early video of with Judy Foster where they showed the application of mental training to cross country runner is a classic. Her sport psychology counseling firm, Porter Performance Systems, a sports and organizational counseling firm, is located in Eugene, Oregon She teaches mental training 
techniques to businesses, school districts and teams. She has also worked as a consultant in sport psychology to the University of Oregon Athletic Department, the U.S. Tennis Association and US track and Field. Dr. Porter is a talented speaker and has made many keynote addresses at the women in business, Wellness conferences, Women's Olympic Marathon Trials, and sales conferences. She has been the sport psychologist at marathoners in Houston, Boston, and Pittsburgh. Dr. Porter is an executive coach and psychotherapist in private practice. She has authored or co-authored The Mental Athlete: Inner Training for Peak Performance (Human Kinetics, 2003), Inner Mental Training for Women, and Visual Athletics (1990) W.C. Brown. Dr. Porter has co-produced two teaching videotapes, "Change Your Mind: Inner Mental Training for women in Business, and "The Mental Athlete". Dr. Porters has also created audiotapes and CDs of guided visualizations for stress reduction, goal achievement, and healing of sports injuries.

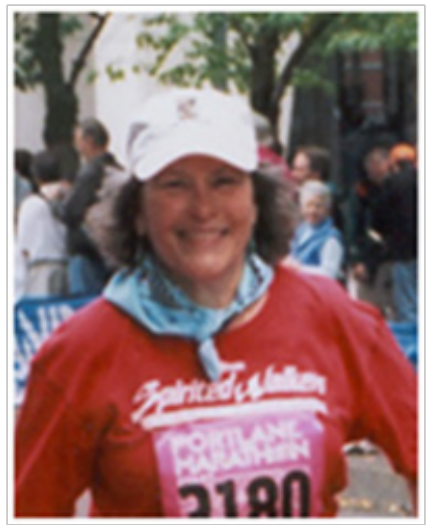

Terry Orlick, ${ }^{36}$ Canadian sport psychologist, is one of the most talented mental trainers in the world. His contributions to sport psychology are legendary. Terry, as he likes to be called, is known for his humanistic style and ability to generate enhanced performance from athletes in a wide variety of sport situations. He founded the Zone of Excellence and is world renowned leader in coaching and teaching people how to perform to best of their ability. In brief, Dr. Orlick puts joyfulness in the lives of his clients. A leader the field of focus training for enhanced performance, He has bridged multiple disciplines for over 35 years. Dr. Orlick has consulted with thousands of corporate leaders, professional and Olympic athletes, top classical musicians, surgeons, athletes and coaches, astronauts, dancers, opera singers and other performing artists, mission control professionals, and many others person who are in high stress performance missions. Terry, as he likes to be called, teaches the key psychological links to excellence that are required for quality living and exceptional performance to teenagers, and children, and persons of all ages. Despite his busy consulting schedule, Dr. Orlick has committed much of his life to helping children and teenagers. Under his direction they grow and perform with self-confidence and an increased sense of harmony and joy in their lives. The author of more than 200 articles, Dr. Orlick's 8 audio CDs and his 24 books have sold over more than a million copies of copies worldwide. His best-selling texts include: In Pursuit of Excellence, Embracing Your Potential, Positive Living Skills, Feeling Great, and others.

Ken Ravizza brought a unique and humanistic style to his approach to mental training. A professor of Applied Sport Psychology at the California State University at Fullerton, Dr. Ravizza is one of the top Peak Performance experts in the world. His educational approach to performance enhancement uses mental skills that coaches, athletes and performers of all levels achieve success on a regular basis.
Ravizza is a leading authority on stress management and coping skills and strategies, Dr. Ravizza is also highly skilled in mental training for Peak Performance. As a consultant to numerous teams, Dr. Ravizza has worked with some of the best athletes and coaches in the world.

Ken Ravizzi's professional sports clients include: the New York Jets. Los Angeles Angels of Anaheim, Los Angeles Dodgers, Los Angeles Galaxy, and the Toronto Argonauts. Ravizza is also one of the most experienced consultants at the Olympic and international level having worked with the United States Olympic, Field Hockey, Softball, Equestrian, Baseball, Water Polo, and Figure Skating Associations for over 20years.
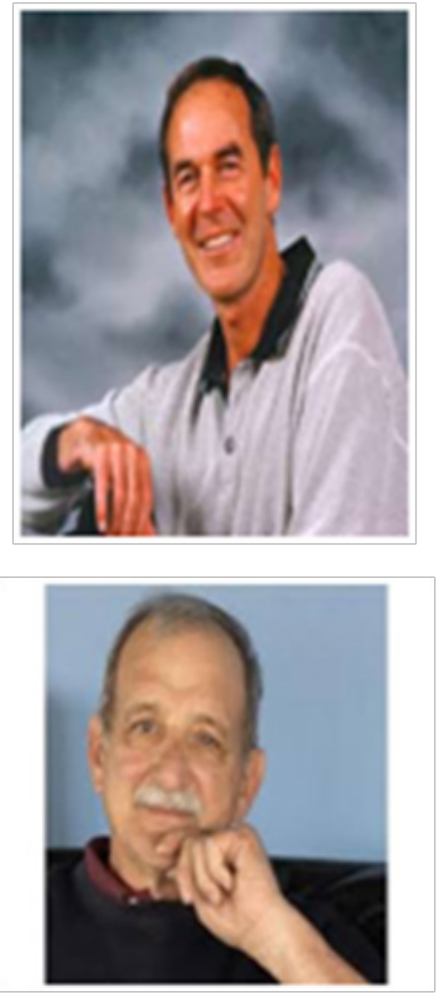

One of the most influential sport psychology in getting sport psychology practices off the ground is Dr. Shane Murphy. Shane is a licensed psychologist and associate professor of Psychology at Western Connecticut State University. He is the founder of Gold Medal Psychological Consultants, which teaches business and sport organizations the competitive skills that lead to success. He has held many outstanding positions, e.g., head of the U. S. Olympic Committee's Sport Psychology Department from 1987 to 1994 and from 1992 to 1994 he was associate director of the USOC Sport Science Division. Dr. Murphy was sport psychologist for the U.S. Olympic Teams at the 1988 Summer Games in Seoul and the 1992 Winter Games in Albertville. He was also a worked with the U.S. Olympic Committee on mental excellence for the 2000 Summer Games in Sydney, and the USA snowboard mental preparation leading up to the 2002 Winter Games in Salt Lake City. His contributions also include numerous books and scientific journals on sport human performance and sport psychology. Dr. Murphy has authored or co-author of five books, including: "The Sport Psych Handbook: Complete Guide to Today's Best Mental Training Techniques" (2005), "The Cheers and the Tears: Positive Alternative to the Dark Side of Youth Sports Today".

The co-founder of the Human Performance Institute, Dr. Jim Loehr (2012) is a world-renowned performance psychologist, and the writer of 16 books including his most recent, The Only Way to Win. And, 
"The Power of Full Engagement" was also co-written by Dr. Loehr. His science-based energy management training system achieved world-wide recognition by leading authorities. Business Week, Harvard Business Review, Time, Fortune, Newsweek, US News and World Report, Success, Omni, and 0ther leading publications have written about his work. NBC's Today Show, ABC's Nightline with Ted Koppel, the CBS Evening News with Dan Rather and CBS Morning News and the Oprah Winfrey Show have had Dr. Loehr appear on their programs. After more than 30years of experience, Dr. Loehr believes the single most important factor in successful achievement, personal fulfillment and life satisfaction is the strength of one's character. ${ }^{37}$ According to Loehr, character can be developed the same way that strength is improved, i.e., hard work. He has consulted with hundreds of world-class performers from the arenas of business, sport, law enforcement, medicine, including The FBI, Fortune 100 executives, and military Special Forces. Corporate clients of the Institute represent hundreds of Fortune 500 companies including Dell, Procter \& Gamble, The Estée Lauder Companies, PepsiCo, FBI, GlaxoSmithKline, and Citigroup Smith Barney. A sampling of Dr. Loehr's clients include: Mark O'Meara and Justin Rose; Monica Seles, Tim Courier, and Arantxa Sanchez-Vicario; Ray Mancini; Mike Richter and Eric Lindros and Mike Richter. Dan Jansen, Olympic gold medal speed skate, is perhaps his most favorite client. Dr. Loehr credentials are impressive. He has masters and doctorate degrees in psychology along with a pleasing personality that enables him to establish rapport with clients from diverse backgrounds. He is a member of several prestigious scientific boards including the National Strength and conditioning Association, the American Psychological Association, the American College of Sports Medicine, and the Association for Applied Sport Psychology.
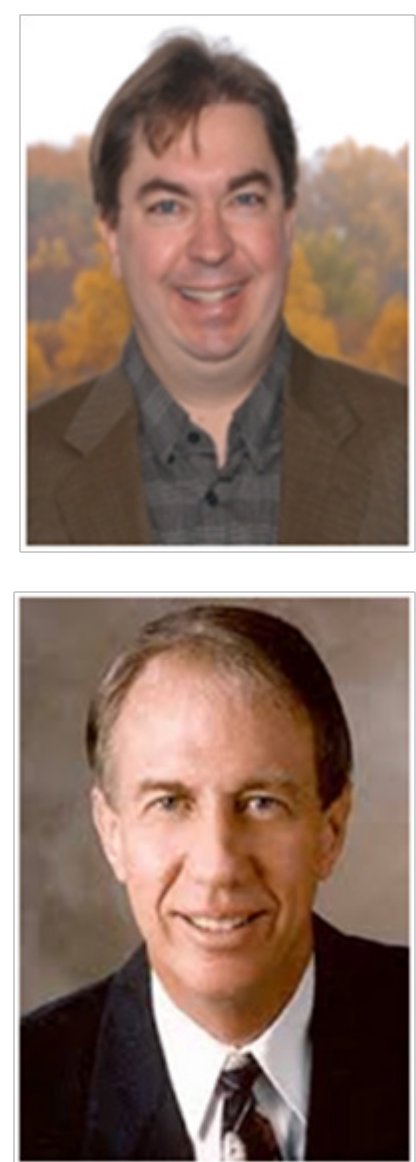

A $\mathrm{PhD}$ graduate from Vanderbilt University, Dr. Robert M. Nideffer is a clinical and experimental psychologist. At the University of Rochester, he was an associate professor in the Department of Psychology and Psychiatry. Dr. Nideffer was also a part-time professor in the department of physical education and psychology at San Diego professor and a professor at the California School of Professional Psychology. He has written seventeen books and authored over one hundred research and applied articles. Described as "a landmark test", Dr. Nideffer's book: The Inner Athlete was published in 1976. In Psyched to Win (1976), his second book, he provides information about how to develop your own mental training program. Dr. Nideffer is the founder of Enhanced Performance Systems. His consulting experiences include work with the Olympic training Centers around the world, Australian Institute, and Canada's national and elite-level coaches and players. He helps teams develop computer software and psychological assessment programs for athletes. At the 1984 Olympic Games, Dr. Nideffer was the sport psychologist for track and field athletes. He also serves as a consultant to police and military, and multinational corporations. An authority in perception, Dr. Nideffer authored: Theory of Attentional and Interpersonal Style.

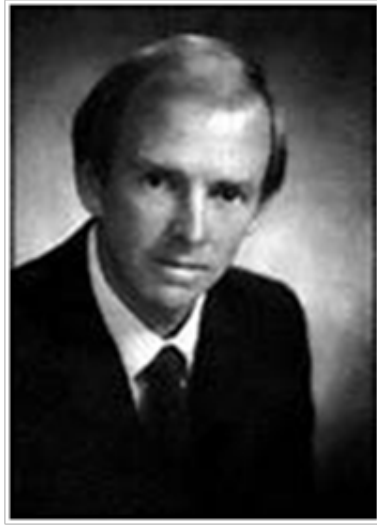

Psycho-Cybernetics is a self-help book, written by Maxwell Maltz in 1960 and published by the non-profit Psycho-Cybernetics Foundation. Many self-help and motivational experts in personal development, including, Zig Zigler, Tony Robbins, Brian Tracy have based their techniques on Maltz's work. Psycho-cybernetics serves as the foundation for many of the psychological methods of training elite athletes. Dr. Maltz's text combines the cognitive behavioral technique of teaching an individual how to regulate selfconcept. Maltz's work in self- concept is based on the teaching of Prescott Lecky with the cybernetics of Norbert Wiener and John von Neumann. The core in his book defines the mind-body connection as the core in succeeding in attaining personal goals. Some of his patients had expectations that were not satisfied by surgery so Maltz ${ }^{38}$ so he used visualizations to help them get better. He was a firm believer in goal setting and why they work. He also used self-affirmation and mental visualization techniques to establish a connection between mind and body. Maltz's procedures developed a positive inner goal as a way of developing positive outer objectives. He believed that a person's outer success is brought about by one's inner attitudes. In summary, Maltz indicated that a person's outer success can never rise above the one visualized internally.

If you were to watch the trophy presentation at a major golf championships, you would hear the trophy winners thank Dr. Bob Rotella. He is one of the world's outstanding sport psychologists and coach of high performance athletes. A reporter described him as akin to a Sherpa, the Nepalese guide who helps mountaineers reach the summit of Mt. Everest. That is essentially what Rotella does: He help 
athletes achieve performances that they could not otherwise reach. Essentially, he unlocks their potential. As the world's preeminent sports psychologist and performance coach, Dr. Rotella indicates that there's nothing mysterious about his approach to performance enhancement. His philosophy is grounded in free will, persistence, commitment, and confidence. According to Rotella, these values were learned as a boy and high school athlete in Rutland, Vermont. These values were reinforced as he watched famous coaches like Red Auerbach and Vince Lombardi. According to Rotella, these principles apply not just to sport, but too many endeavors. His client's say that Rotella's gift is his ability to figure out how clients will best understand and adopt these principles. Through his books and audio recordings, Dr. Bob Rotella's insight and knowledge are available to the public. His bestselling test is: Golf Is Not a Game of Perfect. Sports Illustrated ranked it among the ten best golf instruction books ever written. This book was followed by six other books, each exploring a different aspect of the game.
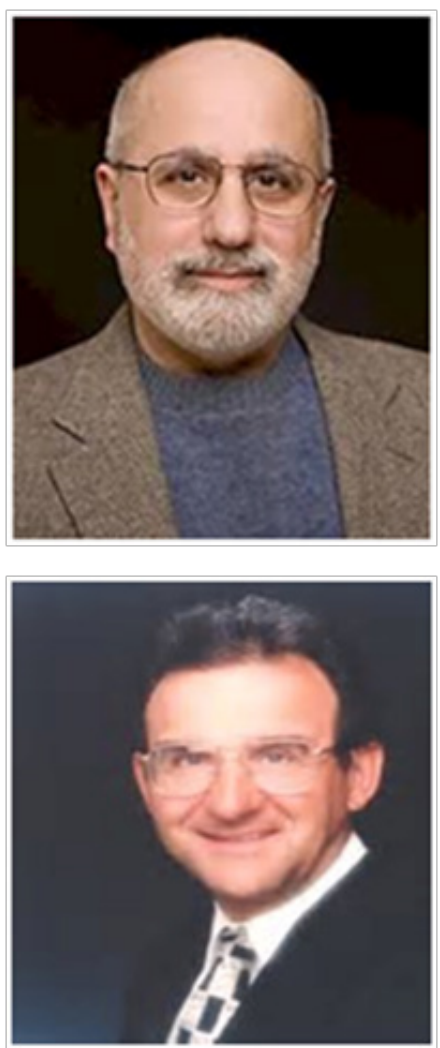

With increasing interest in the applied aspects of sport psychology, particularly mental training programs, within the last ten years there have been a significant number of MT programs for athletes. One of the first programs that I remember was designed and implemented by Bruce Ogilvie, Tom Tutko and Leland Lyon, They developed the Athlete Motivational Inventory (AMI) at the Institute for the Study of Athlete Motivation at San Jose State University. According to the authors, the AMI measured eleven personality traits related to high athletic achievement, including, Drive, Aggression, Determination, Responsibility, and Leadership. As I recall, the AMI was mailed to coaches and the coach had each plyer complete the test and then mail it to the authors for scoring and analysis. Coaches would then receive a written paragraph for the authors about how to handle each player. Despite the AMI popularity, Rainer Martens, University of Illinois sport psychologist, questioned the validity of the AMI and it was taken off the market.
Another early leader in the sport psychology movement was Dr. Charles Garfield. ${ }^{39}$ A fellow of the American Psychological Association, Dr. Garfield was a Clinical Professor of Psychology in the Department of Psychiatry at the University of California's School of Medicine at San Francisco. His peak performance program was outlined in his1984 book: Peak Performance. In this text, states that most athletes will acknowledge that 60 to 90 percent of success in sports is due to mental factors and psychological mastery. Taking the best practices and research from the USA, East Germany, and elsewhere, Dr. Garfield designed a training program consisted of six key lesson in mental training. They were: Lesson 1 Sports Motivation Analysis, Lesson 2 Unveiling your Mission, Lesson 3 Voluntary Relaxation, Lesson 4 Mental Rehearsal, Lesson 5 Athletic Poise, and Lesson 6 Letting go. He suggested that mental trainers should speak slowly and clearly and speak in a soothing voice, keeping consonants soft Washington sport psychologists Ronald Smith and Frank Smoll focused their attention on the coaching of young athletes, i.e., Little League Players. Over many years, Smith and Smoll have done extensive work in youth sports. Most importantly, they have studied the effects of coaching and parent behaviors on child athletes and developed and assessed intervention programs for coaches and parents. Their emphasis is that coaches should try and create a more positive psychological environment for young athletes. Their Youth Enrichment in Sports Project and produced DVD-based instructional programs for coaches and parents on how to create a motivational climate that facilitates the well-being of young athletes. Dr. Smith's current work focuses on the use of assessment information from personality tests (e.g., the MMPI-2) and an online daily diary system as therapeutic feedback in psychotherapy. Currently, Dr. Smoll addresses such important topics as: Can Coaches Increase Their Effectiveness? To answer this question, Dr. Smoll draws-on his 35years of research on coaching behaviors and their effects on young athletes. Smith and Smoll have developed A Sport Psychology Training Program and tested in effectiveness. The program, which is known as the Mastery Approach to Coaching, is the only scientifically validated coachingeducation program for young athletes. When it comes to youth sports, Smith and Smoll are in a league all their own!
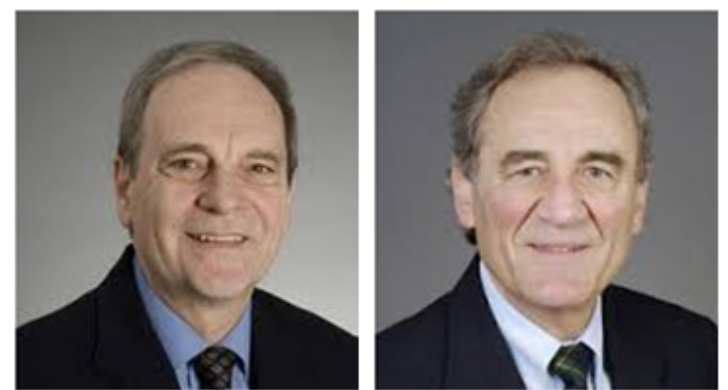

\section{The future of sport hypnosis}

John and I are very excited about the future of sport hypnosis! And as mentioned above, we see sport hypnosis as taking mental training to a higher level. From our professional experiences, we both believe that sport hypnosis is more effective than mental training because athletes obtain a deeper level of relaxation so that their minds may be programed. The importance of obtaining deep levels of relaxation in order to get into trance has been found to be more effective that traditional methods of relaxation. Goals set in trance have been found to be more useful (Liggett, 2000b). When in trance, visualizations appear to clearer, focused and stable that when used in traditional mental training. According to Liggett, the unconscious and the emotional right-brain functions become more available in trance. It should be point-out; however, that hypnosis is not a type of therapy, 
e.g., psychoanalysis. When used by sport psychologists, hypnosis is a technique used to enhance performance and help athletes to enjoy and profit from their sporting experiences.

As cited above, there is a long history in the use of hypnosis in sport by coaches and sport psychologists at most all levels of athletics. For example, it was reported that during the 1956 Melbourne Olympics the Russian team took no less than 11 hypnotists to the games. Countless examples could be cited, however, it is clear evident that sport hypnosis is growing in popularity. However despite its long history, the future of sport hypnosis depends on getting rid of the tarnishing image of the Stage hypnosis, i.e., a hypnotist walks into a crowded auditorium, snaps his fingers and half the audience falls into trance and begins quacking like ducks. That is the image that most have stored in memory when the work 'hypnosis' is mentioned. This visualization of the Stage hypnotist instills fear and misunderstanding into the minds of athletes and others, who would like to use hypnosis to alleviate fear, instill confidence or alleviate mental blocks. For sport hypnosis to become more useful, the image of the Stage hypnotist has to be demystified. What we need is more scientific evidence and case studies that demonstrate the usefulness of hypnosis for athlete and coaches. Additionally, we need to show how sport hypnosis may be used to control arousal levels, set goals, eliminate blockage, image, and enhance performance in a wide variety of sports in controlled environments and in actual competitions. Sport hypnotists are also encouraged to use their own creativity to show how hypnosis may be of value to individual team members and the team as a whole. For example, we want to use hypnosis to help figure skaters do double axels, spins, flips, Sal chows, and other simple and complex skills.

This other side of hypnosis is less known. Few people know about the use of hypnosis in medicine, dentistry and controlling clients with psychiatric problems. For example, before chemical anesthesia, hypnosis was used during surgery. Even today, hypnotists go into dental offices and hypnotize patients who are unable to take medicine to help alleviate pain. Hypnotism is now recognized by the American Medical Association (AMA). Looking forward there is a growing perception that increased availability and awareness of sport hypnosis can take mental training to a higher level. An example of this can be seen by utilizing sport hypnosis in specific consultation situations where trance phenomenon are particularly effective in achieving a desired outcome such as helping athletes re-create training experiences with greater clarity and richness than by employing memory alone. It has been the experience of one of the authors (JB) that this is particularly effective in assisting gymnasts who are hampered by Balking (freezing) when tumbling by having them reconnect to the enthusiasm and curiosity they experienced when first learning this skill. Another example would be using hypnotic imagery to further enhance motor learning by heightening the sensory awareness of the learning when activating low-level neuromuscular innervations during mental rehearsal.

In addition to the need for increased awareness of the value of sport hypnosis it is also essential that the stigma of hypnosis as a "stage act" be overcome. Several factors can contribute to this moving forward including

i. establishing an evidence-based practice model where practitioners can contribute to protocols for specific applications;

ii. integrating hypnosis and hypnotherapy training by professionals from the American Society for Clinical Hypnosis into sport psychology conferences;

iii. increased visibility on the internet (websites/you tube/vimeo) of basic information and models of sport hypnosis and its benefits.
In summary, sport hypnosis will continue to grow in both application and acceptance through the dedicated work of both researchers and practitioners in demonstrating its validity as a modality for change, growth and performance.

\section{Acknowledgments}

None.

\section{Conflicts of interest}

Author declares there are no conflicts of interest.

\section{Funding}

None.

\section{References}

1. Edgette JH, Rowan T. Winning the mind game: Using hypnosis in sport psychology. Bethel, CT: Crown. 2003.

2. Robertson D. Definitions of hypnosis by important organizations and famous hypnotherapists. The UK College of Hypnosis and Hypnotherapy, London. 2002.

3. Braid J. Neurypnology; or, rationale of nervous sleep considered in relation to animal magnetism and illustrate by numerous cases of successful application in the relief and cure of disease. London: George Redway. 1899.

4. Bernheim H. Suggestive therapeutics: A treatise on the nature and uses of hypnotism. New York: GP Putman's Sons. 1900.

5. Bernheim H. Hypnotism, suggestion, psychotherapy: New Studies Doin. 1884.

6. Freud S. The complete psychological works of Sigmund Freud. Vintage New York, USA. 1905.

7. Erickson M. The history of hypnosis. Irvington, New York, USA. 1901

8. Erickson M. The collected papers of Milton H, Erickson on hypnosis Somerset, Wiley and Sons, New Jersey, USA. 1980.

9. Paccagnella M. Demystifying sport hypnosis. Sport Coach. 2004;27:1.

10. Wikipedia. Sport hypnosis defined. 2015

11. Liggett DR. Sport hypnosis. Champaign, IL: Human Kinetics. 2000.

12. Morgan WP. Hypnosis in sport and exercise psychology. In JL Van Raalte and BW Brewer (Ed. Exploring Sport Psychology. Washington DC, USA. 1996. p.107-130.

13. Weinberg R, Gould D. Foundations of sport and exercise psychology Champaign, IL: Human Kinetics. 1995.

14. Martens R. Successful coaching (4th Ed.), Champaign, IL: Human Kinetics. Kinetics. 2012

15. Horn T. Advances in sport psychology (3rd Ed.), Champaign IL: Human Kinetics. Hull C Hypnosis and suggestibility: An experimental approach. Williston, VT: Crown. 2008

16. Williams JM. (Ed). Applied sport psychology. Palo Alto, CA: Mayfield. 1986

17. Cowan HM. The effect of active and passive hypnotic inductions on improving reaction tine in NCAA basketball players. Unpublished doctoral dissertation, Indiana, University of Pennsylvania. 2010.

18. Jacobs WB, Gotthelf C. Effects of hypnosis on physical and athletic performance. In FA De Piano and C Salzberg (Eds.), Clinical applications of hypnosis. Norward, Ablex, New Jersey, USA. 1986.

19. Morgan WP. Hypnosis in sport and exercise psychology. In JL Van Raalte and BW Brewer (Ed. Exploring Sport Psychology. Washington DC, USA. 1996. p.107-130. 
20. Morgan WP. Psychophysiology of self-awareness during vigorous physical activity. Research Quarterly for Exercise and Sports. 1981;52:385-427.

21. Morgan WP, Hirota K, Weitz GA, et al. Hypnotic perturbation of perceived exertion: Ventilatory consequences. Am J Clin Hypn. 1976;18:182-190.

22. Taylor J, Horevitz R, Balague G. The use of hypnosis in applied sport psychology. Sport Psychologist. 1993;7(1): 58-78.

23. Jackson JA, Glass GC, Camp EM. The relationship between Posthypnotic suggestion and endurance in physically trained subjects. The International Journal of Clinical and Experimental Hypnosis. 1979;27(3):278-293.

24. Jacobs WB, Gotthelf C. Effects of hypnosis on physical and athletic performance. In FA De Piano and C Salzberg (Eds.), Clinical applications of hypnosis. Norward, Ablex, New Jersey, USA. 1986.

25. Pates J, Maynard I, Westbury T. An investigation into the effects of hypnosis on basketball performance. Journal of Applied Sport Psychology. 2001;13(1):84-102.

26. Pates J, Oliver R, Maynard I. Effects of hypnosis on flow states and golf performance. Percept Mot Skills. 2001;91(3f):1057-1075.

27. Grindstaff JS, Fisher LA. Sport psychology consultants' experience of using hypnosis in their practice: Exploratory investigation. The Sport Psychologist. 2006;20(3):368-386.

28. Cowan HM. The effect of active and passive hypnotic inductions on improving reaction tine in NCAA basketball players. Unpublished doctoral dissertation, Indiana, University of Pennsylvania. 2010.
29. Duncan D. Using hypnosis to enhance sporting performance. Australia: Surf Life Saving. 2006.

30. Barabasz A, Barabasz M, Bauman J. Restricted environmental stimulation techniques improve human performance: Rifle marksmanship. Percept Mot Skills. 1993;76(3 Pt 1):867-873.

31. Taylor J, Horevitz R, Balague G. The use of hypnosis in applied sport psychology. Sport Psychologist. 1993;7(1):58-78.

32. Kirsch I, Lynn SJ, Rhue J. An introduction to clinical hypnosis. In: JW Rhue, SJ Lynn, \& I irsch (Eds.). Handbook of clinical hypnosis. Washington DC: American Psychological Association. 1997. p.32.

33. Smith ML, Glass GV, Miller TI. The benefits of psychotherapy. Baltimore: Johns Hopkins University Press. 1980.

34. Barker J, Jones MV, Greenlees I. Using hypnosis to enhance selfefficacy in sport performers. Journal of Clinical Sport Psychology. 2013;7:228-247.

35. Orlick T. The pursuit of excellence. Champaign, IL: Human Kinetics. 1980.

36. Loehr J. The only way to win. Hachette, New York, USA. 2012.

37. Maltz M. Psycho-Cybernetics. Wilshire, UK. 1960.

38. Garfield C. Peak performance: Mental training techniques of the world. Warner, New York, USA. 1985. 